\title{
POR QUE AINDA SE ENSINA GRAMÁTICA NAS ESCOLAS?
}

\section{Liane Dal Molin Wissmann}

\section{RESUMO}

Neste artigo tenho como principal objetivo discutir algumas noções iniciais sobre o por que de ensinar a gramática normativa nas escolas. Primeiramente faço um apanhado geral sobre alguns dos principais argumentos que vão contra a gramática normativa, sua estrutura e noções que utiliza. Logo em seguida trago o estudo de Vygotsky que aborda o tema, bem como suas argumentações e justificativa a favor do ensino da gramática às crianças. Concluo com algumas sugestões de autores como Bagno, Fávero e Zozzoli, de como esse ensino poderia ser mais bem desenvolvido e trazer resultados mais producentes.

\section{UMA RÁPIDA CONTEXTUALIZAÇÃO}

Poucas são as situações em nossa vida que se repetem de forma a nos oferecer a chance de optar por aquilo que, na primeira vez, foi deixado de lado em detrimento de outra escolha. No entanto, aqui estou eu, com esta oportunidade que me enche de alegria. Há pouco mais de um ano escrevi um artigo ${ }^{1}$ que falava sobre a gramática normativa (ou tradicional), seu histórico e concepções e, para início de conversa fiquei tentada a utilizar-me de dois textos de Luís Fernando Veríssimo. Entretanto, por achar que estaria abusando de sua criatividade, tão generosamente compartilhada conosco, optei por utilizar apenas um de seus textos. Hoje, quando novamente volto a escrever sobre gramática, a tentação é maior que meus pudores e trago um trechinho para meu leitor, utilizando uma vez mais as geniais histórias de Veríssimo para ilustrar as possíveis situações e os "apertos" pelos quais passamos ao ter que falar ou explicar as "normas" de nossa língua, de acordo com a gramática tradicional.

O referido texto inicia com o filho perguntando ao pai "Como é o feminino de sexo?" e o pai respondendo: "Não tem". A partir daí o menino, incisivamente, solicita explicações para um assunto que o pai não consegue, definitivamente, explicar:

\footnotetext{
${ }^{1}$ Este artigo encontra-se publicado na revista "Formas \& Linguagens", $n^{\circ} 4$, out./dez. 2002, intitulado "Conversando sobre gramática e ensino".
} 
"- Sexo não tem feminino?

- Não.

— Só tem sexo masculino.

—É. Quer dizer, não. Existem dois sexos. Masculino e feminino.

- E como é o feminino de sexo?

— Não tem feminino. Sexo é sempre masculino.

— Mas tu mesmo disse que tem sexo masculino e feminino".

E a conversa vai e vem sem que o pai possa arrumar um jeito de fazer com que seu filho entenda porque a palavra sexo só existe no masculino apesar de existir o sexo feminino e o masculino:

“- Então como é o feminino de sexo?

-É igual ao masculino.

- Mas não são diferentes?

— Não. Ou, são! Mas a palavra é a mesma. Muda o sexo, mas não muda a palavra.

— Mas então não muda o sexo. É sempre masculino.

- A palavra é masculina.

— Não. "A palavra" é feminino. Se fosse masculina seria "o pal..."

Já sem argumentos o pai desiste da árdua tarefa de explicar a tal diferença entre o que o menino considerava correto distinguir entre "sexo" e "sexa", e o manda brincar. Logo depois, faz uma advertência à mãe do garoto:

“- Temos que ficar de olho nesse guri...

- Por quê?

— Ele só pensa em gramática”. 


\section{ALGUNS ARGUMENTOS INTERESSANTES}

Esta história trazida por Veríssimo poderia, sem dificuldade alguma, ter acontecido em qualquer lar brasileiro e receber o nome de "Dramática da língua portuguesa", como diria Marcus Bagno. Porém, não quero dar uma impressão errada ao leitor, que, ao tomar contato com um texto intitulado "Por que ainda se ensina gramática nas escolas?" e introduz o assunto de forma a explicitar a impotência que vivemos diante de regras e normas que, nem sempre são possíveis de explicar, ficará muito inclinado a acreditar que, o que esta autora quer afirmar é que não se deve ensinar gramática nas escolas ou que esta é uma tarefa ingrata e inglória.

Motivos não faltarão, nem entre alunos e professores, nem entre autores renomados, que poderiam sustentar uma argumentação nesse sentido. Silva (2000, p 12-14), por exemplo, afirma que a gramática peca ao dar precedência a língua escrita e uma determinada variedade como a melhor, reforçando o dialeto da elite e silenciando outros usos. Também encontramos Rocha (2002), para quem o grande problema da "gramaticologia brasileira" é afirmar que as regras da gramática são baseadas nas obras literárias dos escritores brasileiros e portugueses, o que é um equívoco se considerarmos seus regionalismos, idiomatismos e coloquialismos.

Porém, o mais incisivo de todos ainda é Bagno (2001), ao afirmar que as classificações, terminologias, conceitos e definições da gramática normativa não são hipóteses científicas postas à prova em experimentações empíricas, constituindo-se em teorizações dos fenômenos da linguagem. De acordo com o autor, os conceitos apresentados ainda hoje são os mesmos de gerações passadas, não contemplando a forma de se expressar dos indivíduos atualmente; não leva em conta a investigação do fenômeno da linguagem, tentando compreender a relação entre língua e pensamento e o exame das relações que as pessoas estabelecem entre si por meio da linguagem; desconsidera a língua falada; traz consigo noções de "certo" e "errado", refletindo esquemas sociais de autoritarismo e intolerância aos quais as pessoas devem adaptar-se sem questionamentos; é elitista uma vez que considera "feio", "estropiado" e "deselegante" tudo o que não se encaixa no seu "sapatinho de cristal"; tem a pretensão de servir de régua para a língua, esquecendo-se que é baseada apenas na produção escrita literária e, desta forma, deveria servir de parâmetro apenas para esta modalidade de produção; nunca avança para além da frase e os 
sujeitos não falam por frases, mas, por textos, cheios de significados (semântica), produzindo efeitos (pragmática).

\section{POR QUE, ENTÃO, ENSINAR GRAMÁTICA?}

Como pudemos ver até aqui, o que não nos falta são argumentos para que o ensino da gramática seja repensado. No intuito de contribuir com esta reflexão quero trazer aqui a teoria experimental de Vygotsky (1999, p. 122), que trata das relações entre aprendizado e desenvolvimento, abordando em especial a área do aprendizado escolar referente à gramática².

Como o próprio autor afirma, "a gramática é um assunto que parece ter pouca utilidade prática", assim como a escrita quando passa a ser ensinada porque a criança não sente nenhuma necessidade real ou iminente delas (gramática e escrita), apenas uma vaga idéia de suas utilidades. Se na escrita a criança passa a ser exigida de que crie situações, tome consciência da estrutura sonora de cada palavra, disseque-a e reproduza-a em símbolos alfabéticos, que devem ser anteriormente estudados e memorizados, organizando-os em palavras seqüenciadas para formar uma frase; no estudo da gramática a criança não aprende novas habilidades, pois já conjuga e declina antes de entrar na escola (op.cit., 1999, p. 125).

Entretanto, Vygotsky afirma ter sua análise mostrado claramente que "o estudo da gramática é de grande importância para o desenvolvimento mental da criança" (idem). Isso se dá pelo fato de que, embora domine a gramática de sua língua muito antes de entrar na escola, esse domínio é inconsciente, ou seja, mesmo usando o tempo verbal correto ao se expressar, não saberá declinar ou conjugar uma palavra quando isso Ihe for solicitado. Nesse sentido, o ensino da gramática torna-se válido não só porque permite à criança estar consciente do que está fazendo, mas porque aprende a usar estas habilidades de forma consciente, além de permitir a ela passar para um nível mais elevado do desenvolvimento da fala.

\footnotetext{
${ }^{2}$ A teoria experimental de Vygotsky foi formulada com base nas relações entre aprendizado e desenvolvimento, partindo de quatro séries de investigações cujo objetivo era averiguar as interrelações em áreas definidas do aprendizado escolar, a saber: leitura e escrita, gramática, aritmética, ciências sociais e ciências naturais.
} 
Vygotsky ressalta ainda que

o aprendizado de uma matéria influencia o desenvolvimento das funções superiores para além dos limites dessa matéria específica; as principais funções psíquicas envolvidas no estudo de várias matérias são interdependentes - suas bases comuns são a consciência e o domínio deliberado, as contribuições principais dos anos escolares. A partir dessas descobertas, conclui-se que todas as matérias escolares básicas atuam como uma disciplina formal, cada uma facilitando o aprendizado das outras; as funções psicológicas por elas estimuladas se desenvolvem ao longo de um processo complexo. (Vygotsky, 1999, p. 128)

Ainda, cabe salientar aqui que nenhum dos autores citados anteriormente posiciona-se contra o ensino da gramática, porém, seus argumentos vão no sentido de que este ensino aconteça através de formas alternativas como, por meio de reflexões feitas a partir das próprias dificuldades surgidas da escrita ou reescrita de textos (Zozzoli, 1999); da análise lingüística a partir do texto, considerando relações textuais, intertextuais e contextuais pelo manuseio pragmático da linguagem escrita, contemplando não só textos clássicos mas também modernos, em diferentes contextos e situações e partindo do nível lingüístico no qual se encontra o aluno (Fávero, 1994); ou ainda como propõe Bagno (2001), através da "pesquisa lingüística", que parte do conceito da gramática normativa para então fazer uma reflexão-investigação do fenômeno numa perspectiva histórica, utilizando textos como corpus, investigando a língua viva através de entrevistas, por exemplo, e a elaboração de conclusões que permitam criticar a gramática normativa e elaborar regras da língua em uso.

Para todos esses casos, aplica-se ainda a pesquisa de Vygotsky (1999, p. 126), que postula: "o aprendizado tem suas próprias seqüências e sua própria organização, segue um currículo e um horário, e não se pode esperar que as suas regras coincidam com as leis internas dos processos de desenvolvimento que desencadeia" e que "com o auxílio de outra pessoa, toda criança pode fazer mais do que faria sozinha. (...) O que a criança é capaz de fazer hoje em cooperação, será capaz de fazer sozinha amanhã" (op.cit., p. 129-130).

Portanto, ao ensinar gramática, tenhamos sempre presente estas questões, que nos orientam na direção de que é necessário levar em conta o capital cultural ${ }^{3} \mathrm{da}$

\footnotetext{
${ }^{3}$ Capital cultural foi empregado aqui no sentido proposto por Bourdieu (apud Clark \& Ivanic, 1997), e engloba língua/linguagem, significados, pensamentos e comportamentos, valores e atitudes. De
} 
criança e incentivá-la no sentido de que aprender pela colaboração é sempre mais válido e producente que aprender pela competição.

\section{BIBLIOGRAFIA}

BAGNO, Marcos. Dramática da língua portuguesa. Tradição gramatical, mídia \& exclusão social. São Paulo: Edições Loyola. 2000.

CLARK. Romy; IVANIC, Róz. The politics of writing. Canada/Estados Unidos: Routledge, 1997.

FAVERO, Teresinha Oliveira. Gramática: objeto descartável? Trabalho apresentado no I Congresso Internacional da Associação Brasileira de Lingüística - 1994, na UFBA, em Salvador/ Bahia.

SILVA, Rosa Virgínia Mattos e. (2000) Tradição Gramatical e Gramática Tradicional. 4a edição. São Paulo: Contexto, 2000. (Repensando a Língua Portuguesa).

VERÍSSIMO, Luis Fernando. Sexa. In: Comédias para se ler na escola. Rio de Janeiro: Objetiva, 2001. pg. 53-54.

ZOZOLI, Rita Maria Diniz. O processo de constituição de uma gramática do aluno leitor/produtor de textos: a busca de autonomia. In: Trabalhos em Lingüística Aplicada, Número 33, Jan./Jun. 1999. Campinas (SP): UNICAMP/IEL - Setor de Publicações. Pg. 07-21.

VYGOTSKY, L. S. Pensamento e Linguagem. Tradução de CAMARGO, Jefferson Luiz. São Paulo: Editora Martins Fontes, 1999.

acordo com o referido autor, o sistema educacional favorece certo tipo de capital cultural, associado e intimamente ligado à cultura dominante. Este processo resulta em desvantagens para aqueles que não acumulam este tipo de capital cultural e acabam por ter sua própria cultura desvalorizada e negada. Seus conhecimentos cotidianos, modo de falar e escrever, suas roupas, tudo se torna marginalizado e inferiorizado no contexto escolar. Ao contrário, crianças advindas de famílias de classe-média chegam à escola com o tipo certo de capital cultural e, é por intermédio desta educação que eles acumulam ainda mais riqueza cultural. A exemplo do ditado: dinheiro gera dinheiro; capital cultural também gera mais capital cultural. 